\title{
Análisis de creencias sobre el rol docente en estudiantes chilenos de pedagogía en inglés a través de la metáfora conceptual ${ }^{1}$
}

\author{
Analysis of Beliefs on The Teacher's Role on Chilean EFL \\ Pre-Service Teachers Through Conceptual Metaphor
}

\author{
Paola Alarcón Hernández \\ Jorge Vergara Morales \\ Claudio Díaz Larenas \\ David Poveda Becerra ${ }^{2}$
}

\section{Resumen}

Esta investigación de tipo cualitativo tiene como objetivo analizar las categorías metafóricas sobre el rol docente en estudiantes de pedagogía en inglés de una universidad chilena. Se describen las metáforas conceptuales en un grupo de $1 .{ }^{\text {er }}$ año y en uno de $5 .^{\circ}$ año relativas a: 1 ) sus creencias sobre la imagen social del rol docente y 2) su imagen sobre el rol del profesor de inglés. Al interior de cada grupo, se comparan las categorías de metáforas obtenidas. Luego se establecen diferencias en las categorías de metáforas entre los estudiantes

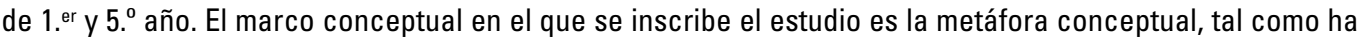
sido abordada por la lingüística cognitiva. En la metodología, para la elicitación de metáforas, se aplicó un cuestionario; luego se realizó un análisis de contenido, que abarcó las siguientes etapas: categorización, clasificación y juicio de externos. Con respecto a los resultados sobre la imagen social del rol docente, se identificaron metáforas centradas en el proceso de enseñanza y aprendizaje. Además, en ambos grupos, los sujetos muestran tener conciencia de la minusvaloración social que recibe la profesión docente. Con respecto a rol del profesor de inglés, en el grupo de 1. er año, la categoría más numerosa es la que configura el rol del profesor como transmisor de conocimientos. En el grupo de estudiantes de $5 .^{\circ}$, hay un predominio de las metáforas centradas en el estudiante.

Palabras clave

Metáfora conceptual, creencias, categoría conceptual, estudiante de pedagogía.

Abstract

This qualitative study aims at analysing the metaphorical categories on teacher role from EFL pre-service teachers at a Chilean university. Conceptual metaphors of a group of first and fifth year pre-service teachers are described, regarding: 1) their beliefs about the social image of the teacher's role and 2) their image on the role of the English teacher. For each group, metaphor categories are compared and then they are analyzed between groups. This study on conceptual metaphor is in the context of Cognitive Linguistics. As for the

1 El estudio que se presenta está inserto en los proyectos "La metáfora conceptual como herramienta de análisis de creencias docentes en profesores de establecimientos educacionales de la comuna de Concepción" (Fondecyt Iniciación, n. ${ }^{\circ}$ 11130482) e "Investigación del conocimiento profesional, las creencias implícitas y el desempeño en aula de estudiantes de pedagogía en inglés como estrategia de generación de indicadores de monitoreo de su proceso formativo" (Fondecyt Regular, n. $\left.{ }^{0} 1120247\right)$.

2 Universidad de Concepción, Concepción, Chile.Correos electrónicos: palarco@udec.cl; jorvergara@udec.cl; claudiodiaz@ udec.cl; dpoveda@udec.cl 
Universidad Pedagógica Nacional

Facultad de Humanidades

research design, a questionnaire is applied to elicit metaphors, content analysis is used, following these stages; categorization, classification and external scholar review. Regarding the results on the social image of the teachers' role, teaching and learning centered metaphors are identified. For both groups, participants are aware of the social undervalue of the teaching profession. As for the role of the English teacher, first year pre-service teachers incline to identify teachers as transmitters of knowledge. Fifth year pre-service teachers, opt for student-centered metaphors.

\section{Key words}

Conceptual metaphor, beliefs, conceptual category, pre-service teacher.

Artículo recibido el 6 de marzo de 2014 y aprobado el 7 de abril de 2015

\section{Introducción}

Esta investigación tiene como objetivo analizar las categorías metafóricas sobre el rol docente en estudiantes de pedagogía en inglés de una universidad chilena. Específicamente, se describen las metáforas conceptuales en un grupo de $1{ }^{\text {er }}$ año y en uno de 5..$^{\circ}$ ano relativas a: 1 ) sus creencias sobre la imagen social del rol docente y 2) su imagen sobre el rol del profesor de inglés. En cada grupo, se comparan las categorías de metáforas obtenidas. Luego se establecen diferencias en las categorías de metáforas entre los estudiantes de $1 .^{\text {er }}$ y $5 .^{\circ}$ año.

En Chile existe una creciente preocupación por la calidad de la educación, la formación de los docentes y las condiciones laborales de los profesores en ejercicio. Esto se manifiesta en medidas para el fortalecimiento de la formación inicial y del desarrollo profesional; perfeccionamientos y evaluaciones al desempeño docente (Sánchez, 2009). Sin embargo, persiste una demanda social por la calidad, financiamiento y equidad de la educación (Simonsen, 2012). Desde distintos sectores políticos y sociales, se reconoce la importancia del movimiento social que el 2011 iniciaron estudiantes secundarios y de educación superior, quienes piden que el estado chileno garantice el acceso equitativo a una educación pública de calidad (González y Montealegre, 2012).

Los niveles primario y secundario son de tres tipos en Chile: público, particular subvencionado (con apoyo económico parcial por el estado) y privado. Las evaluaciones a estudiantes en los niveles primario y secundario en pruebas estandarizadas internacionales evidencian que, pese al incremento en los puntajes, aún Chile está bajo el promedio de los países de la OECD (Brandt, 2010); por otra parte, las evaluaciones estandarizadas nacionales muestran la desigualdad del sistema escolar. Según datos emanados del Ministerio de Educación chileno, los mejores resultados de estas pruebas se encuentran en los colegios particulares, luego en los colegios particulares subvencionados, y, relegados al último lugar, los colegios municipales.

Esta preocupación sostenida por obtener buenos resultados en las evaluaciones repercute en las exigencias a los profesores, a quienes se les asigna un grado de responsabilidad en el desempeño de sus alumnos. A esto se suma que, como señalan Meller y Brunner (2009), los niveles de ingreso de los docentes es inferior al de otras profesiones. Dada estas condiciones, el Estado ha debido emprender iniciativas para lograr que estudiantes con buenos puntajes en la prueba de ingreso a las universidades opten por estudiar carreras de pedagogía, como es el caso de Beca Vocación de Profesor.

Desde una definición primigenia, el docente se incluiría dentro de una conceptualización profesional. Sin embargo, en la práctica, y como se señalará en algunos ejemplos posteriores, se parece cuestionar la profesionalización de la carrera docente y se le denominaría como una cuasi-profesión (Hoyle, 1974, en Ávalos, 2013), debido a que esta debe ceñirse a estructuras muy fijas e institucionalizadas políticamente.

Estos son algunos de los factores que dan cuenta del complejo escenario en el que se desenvuelven los docentes y del desafío que implica estudiar pedagogía. Es por ello que con este estudio preten- 
dimos indagar, a través de la metáfora conceptual, las creencias de estudiantes de pedagogía acerca de la percepción social sobre la profesión docente y las creencias sobre su propia especialidad.

\section{Marco teórico}

\section{Metáfora conceptual}

En esta investigación, la metáfora conceptual constituye una herramienta para recoger y analizar las creencias de los actores del sistema educativo. Las creencias docentes se entienden como "las formas personales en que un profesor entiende a los estudiantes, la naturaleza del aprendizaje, la sala de clases, el rol del profesor en el aula, los objetivos pedagógicos" (Borg, 2003, p. 100). Según diversos autores, comprender la estructura de las creencias de los docentes es esencial en la formación profesional y prácticas pedagógicas (Freeman, 2002; Tillema, 1998; Pajares, 1992). En la actualidad, hay una línea de estudios que indaga en las creencias de los actores del proceso educativo a través de la metáfora conceptual, entre los cuales destacamos los de Eren y Tekinarslan (2013); Wan, Low y Li (2011); Kasoutas y Malamitsa (2009); Northcote (2009); Nikitina y Furuoka (2008); Low (2008); Zapata y Lacorte (2007); Saban (2010, 2006, 2004); Cameron (2003); De Guerrero y Villamil (2001); Cortazzi y Jin (1999); Oxford et al. (1998).

La metáfora conceptual conforma un área de estudio central en la lingüística cognitiva (Soriano, 2012; Grady, 2007), enfoque en que se define el lenguaje como un instrumento para la organización del conocimiento y que se caracteriza por privilegiar las bases de las categorías lingüísticas en el sistema conceptual (Ibarretxe-Antuñano y Valenzuela, 2012, pp. 13-38; Geeraerts y Cuyckens, 2007, pp. 3-21). En términos de Evans y Green, la lingüística cognitiva se basa en la asunción de que el lenguaje refleja patrones de pensamiento. De esta forma, el estudio del lenguaje permite acceder a los patrones de conceptualización de los hablantes (Evans y Green, 2006, p. 5).
En Metaphors we live by, Lakoff y Johnson (1980) destacaron el rol de la metáfora no solo en el plano lingüístico, sino también en nuestra forma de razonar e incluso en el plano de las actitudes y acciones. En la tradición clásica, desde Platón en adelante, la metáfora había sido considerada, principalmente, como un recurso que responde a la creatividad del poeta y del retórico para adornar sus obras.

Desde la perspectiva de la lingüística cognitiva, en cambio, la metáfora se define como un conjunto sistemático de correspondencias entre dos dominios conceptuales que surge de la proyección de elementos, propiedades y relaciones de un dominio más relacionado a la experiencia corporal y social, llamado dominio fuente, a un dominio más abstracto, llamado dominio meta (Soriano, 2012; Kövecses, 2002/2010; Grady, 2007; Lakoff, 1993). Se postula que el conjunto de correspondencias entre ambos dominios produce una lógica particular para cada metáfora mediante la cual razonamos. Estas correspondencias son la base desde donde surgen las manifestaciones de la metáfora. Por ello, no debe confundirse la metáfora conceptual con su expresión lingüística, que es una de sus manifestaciones; otras son las imágenes (Díaz, 2011) y los gestos (Cienki y Müller, 2008).

Para efectos de este estudio, se usará indistintamente los términos metáfora conceptual, concepto metafórico e imagen metafórica, atendiendo a que son formas de denominar un recurso mental para construir conceptualizaciones de la realidad basadas en dominios fuente de carácter más concreto que el dominio meta al que se proyectan.

A partir del trabajo seminal de Lakoff y Johnson se han realizado diversas investigaciones en diferentes ámbitos, tales como la evolución semántica (Sweetser, 1990), el estudio de las emociones (Kövecses, 1990), la psicolingüística (Casasanto, 2014), la lingüística de corpus (Stefanowitsch y Gries, 2006), las matemáticas (Lakoff y Núñez, 2000), la enseñanza de segundas lenguas (Low, 2008), entre muchos otros temas. El desarrollo de este enfoque ha tenido como consecuencia el refi- 
namiento de los métodos específicos para analizar los objetos de estudio particulares.

En cuanto fenómeno cognitivo que estructura nuestra conceptualización de la realidad, el uso cotidiano de las metáforas es inconsciente y automático. No obstante, se pueden detectar distintos grados de uso consciente. En los casos de algunos tipos de discurso, como los presentes en las campañas políticas, puede verse que hay una planificación a fin de lograr objetivos estratégicos, como, por ejemplo, legitimar la propia posición y deslegitimar la posición contraria (Chilton, 2004). Al respecto, se debe señalar que la línea de trabajo que seguimos - y que reseñamos en la sección siguiente- se distancia de los trabajos que analizan la metáfora en situaciones comunicativas reales, ya que las investigaciones se realizan a partir de la elicitación de la metáfora utilizando como instrumento de recolección de datos cuestionarios escritos en los cuales a los sujetos se los induce a producir metáforas.

\section{Metáfora y educación}

En lingüística cognitiva se postula que la proyección de un dominio a otro es parcial, si no se trataría de un mismo dominio. Cada concepto metafórico destaca ciertos aspectos y deja de lado otros, imponiendo una perspectiva particular sobre el dominio meta (Kövecses, 2010). Por ello, el estudio de metáforas conceptuales puede servir como instrumento de análisis de las prácticas y experiencias humanas cotidianas (Oxford et al., 1998, p. 45).

Así, cuando un dominio meta, en este caso el PROFESOR, es configurado metafóricamente a través de la proyección de propiedades de un dominio fuente, por ejemplo PADRE, se produce un concepto específico: EL PROFESOR ES UN PADRE. Este concepto metafórico está conformado por un conjunto de implicaciones y aspectos valorativos e incluso afectivos, como se mostrará en el análisis.

En el tipo de estudios en el que se inscribe la presente investigación, los sujetos justifican la elección del dominio fuente, a través de la completación de oraciones como "el profesor es como... porque...". A través de la justificación es posible identificar los aspectos destacados por cada concepto metafórico. Es allí donde, en estas investigaciones, se infieren las correspondencias.

La literatura especializada muestra que los estudios de metáfora se focalizan en las actitudes de los profesores en formación y en ejercicio hacia las prácticas del aula, la interacción profesor-estudiante, y la evolución de las creencias acerca de la enseñanza y del aprendizaje. Entre los objetivos de este tipo de estudios se encuentra ayudar a los profesores a articular y "construir representaciones sobre sí mismos y sobre sus experiencias" (Kramsch, 2003, p. 125); "promover conciencia sobre la práctica profesional, y mejorar su práctica en el aula" (Cortazzi y Jin, 1999, p. 155). De esta forma, el lenguaje metafórico puede ayudar a los investigadores en educación a comprender el pensamiento profesional de los docentes (Marshall, 1990), ya que se puede utilizar como un instrumento de recolección de datos y también como una herramienta de análisis (Oxford et al., 1998; De Guerrero y Villamil, 2002).

\section{Funciones de la metáfora en educación}

En su revisión de distintos estudios en el campo de la educación, Saban (2006) identifica distintas funciones de la metáfora en la enseñanza y la formación del profesorado. Según este autor, el supuesto básico es que las metáforas proporcionan ventanas al pensamiento y el conocimiento profesional de los profesores. Algunas de estas funciones son las siguientes:

- La metáfora como un medio para indagar en la identidad profesional: Al reflexionar sobre las creencias y los sentimientos, por ejemplo, las metáforas son una fuente válida para la obtención de conocimientos sobre la enseñanza y el aprendizaje desde las perspectivas de diferentes actores del sistema educativo, tal como se muestra en diversos trabajos (Marshall, 1990; Bozlk, 2002; Inbar, 1996; Martínez, Sauleda y Huber, 2001). Algunos estudios concluyen que las metáforas son fundamentales para la búsqueda del sentido de sí mismos, tanto para profesores en ejercicio como para los estudiantes de pedagogía o para la compresión del sen- 
tido de la identidad profesional (Saban, 2004; Thomas y Beauchamp, 2011). Ben-Peretz, Mendelson, y Kron (2003) plantean la interrogante de si los profesores en diferentes contextos de trabajo conciben su rol docente e identidad de manera diferente. Los resultados del estudio avalan el supuesto de que el contexto de enseñanza tiene un impacto significativo en las imágenes profesionales de sí mismos de los profesores.

- La metáfora como medio de reflexión: Un elemento esencial del desarrollo cognitivo es la reflexión. En el estudio de Black y Halliwell (2000) sobre los conocimientos prácticos de enseñanza, 14 profesores australianos de enseñanza preescolar hablaron de sus experiencias docentes, hicieron dibujos de sí mismos como maestros de niños y registraron sus reflexiones en diarios de vida. Luego, utilizaron estas representaciones para examinar críticamente las conexiones entre sus aspiraciones, experiencias, relaciones y sentimientos, y cómo estas entidades han contribuido a su identidad docente. Estos autores concluyen que "becoming conscious of 'images' activated by practical teaching situations is a catalyst for professional growth" (2000, p. 104).

- La metáfora como un gatillador para el cambio: Las metáforas pueden servir como un "interruptor maestro” (Tobin, 1990) para facilitar los cambios en la filosofía personal de enseñanza. Gillis y Johnson han argumentado que cuando un profesor pretende algún cambio pedagógico que esté en armonía con sus objetivos de enseñanza, creencias y filosofía, debe primero "hacer un balance", y la metáfora parece ser un punto de partida ideal en este respecto (2002, p. 38).

- La metáfora en la didáctica de la lengua: Cuadrado y Robisco (2011), citando diversos estudios, destacan la eficacia del uso de la metáfora en el aula, ya que los alumnos "se ven estimulados a categorizar las expresiones metafóricas que, al pertenecer a unos patrones conceptuales, son más fáciles de recordar y almacenar en la memoria a largo plazo que si son elementos aislados" (p. 99).

\section{Metodología}

\section{Muestra de estudio}

Para seleccionar la muestra de estudio se aplicó un tipo de muestreo cualitativo de carácter deliberado e intencional denominado "selección de casos típico ideal", el cual procede de acuerdo al desarrollo de un perfil de atributos esenciales (Rodríguez, Gil y García, 1999; Merrian, 1998; Sealey, 2010). El cuestionario se aplicó a estudiantes de pedagogía en inglés: 29 de $1 .^{\text {er }}$ año y 15 de $5 .^{\circ}$ año. A continuación se presentan los atributos considerados para la selección de la muestra:

a. Ser alumno de 1. ${ }^{\text {er }}$ año. La razón para incluir este atributo se relaciona con la intención de conocer los conceptos metafóricos de estudiantes de 1 . $^{\text {er }}$ año que permitan inferir aquellos elementos que subyacen a la opción de realizar los estudios de una carrera de pedagogía.

b. Ser alumno de $5 .^{\circ}$ año. La razón para incluir este atributo es que se pretende establecer si esta formación tiene algún impacto en sus creencias sobre la docencia, dado que estos estudiantes se encuentran en la etapa final de su formación universitaria, incluyendo la práctica profesional.

c. Ser alumnos de una carrera de lengua. Este atributo fue considerado debido a que el contexto pedagógico de este tipo de carreras posibilita el desarrollo de experiencias del ámbito lingüístico que facilitan la aplicación de la perspectiva de las metáforas.

d. Manifestar la intención consentida de participar en la investigación. 


\section{Técnicas de recolección de los datos}

Se diseñó un cuestionario de metáforas siguiendo la línea de estudios como los de Kasoutas y Malamitsa (2009), Nikitina y Furuoka (2008) en los que se les pide a los sujetos completar oraciones como "el profesor es como... porque...", en las que tienen que formar metáforas conceptuales proponiendo un dominio fuente y entregando una justificación de su elección. Tal como observa Wan (2011), la construcción de este tipo de cuestionario debe resguardar que los sujetos efectivamente utilicen metáforas y de no ser así, explicitar las causas, además se debe procurar que las investigaciones mantengan criterios de validez.

En consecuencia, se elaboró un cuestionario que comienza con una breve definición de metáfora. Luego, se presentan cuatro ejemplos de metáforas, fuera del ámbito de la educación. En seguida se analizan los ejemplos. Dos ejemplos son metáforas bien construidas y los otros dos son ejemplos de metáforas mal construidas, pues corresponden a simples descripciones, esto es, no hay dos dominios conceptuales puestos en relación. Luego de esta explicación se pide que se completen las oraciones:

1. En la sociedad chilena, el profesor en cuanto profesional de la educación es visto como... porque...

2. Según su opinión, en el proceso de enseñanza-aprendizaje de la lengua, el profesor de inglés es como... porque...

\section{Aplicación del instrumento}

En primer lugar se les solicitó su consentimiento para participar en una investigación sobre representaciones metafóricas. Al grupo de estudiantes de 1. ${ }^{\text {er }}$ año se le entregó el instrumento en su aula de clases sin darles un límite de tiempo. Al grupo de estudiantes de $5 .^{\circ}$ año, dado que están en periodo de práctica y no asisten de manera regular a la Universidad, se les envío el cuestionario vía correo electrónico. Se les pidió que en el plazo de una semana lo enviaran de vuelta.

\section{Análisis cualitativo}

Se realizó un análisis de contenido, el cual corresponde a una técnica utilizada para estudiar y analizar los discursos de los sujetos de una manera objetiva y sistemática (Richards, Ross y Seedhouse, 2012). El análisis de contenido puede ser definido como

El conjunto de técnicas de análisis de las comunicaciones tendentes a obtener indicadores (cuantitativos o no) por procedimientos sistemáticos y objetivos de descripción del contenido de los mensajes permitiendo la inferencia de conocimientos relativos a las condiciones de producción/ recepción (contexto social) de estos mensajes. (Bardin, 1996, p. 32)

Para realizar el análisis de contenido se consideraron las siguientes etapas:

1. Preanálisis: Correspondió a la etapa de organización del material a analizar, en la que se diseñaron y definieron los ejes del plan que permitió examinar los datos y realizar efectivamente el análisis.

2. Codificación: Consistió en realizar una transformación de los "datos brutos" (el material original) a los "datos útiles". Las operaciones implicadas en esta etapa fueron la fragmentación del texto, es decir, el establecimiento de unidades de registro, y la catalogación de elementos.

3. Categorización: Consistió en la organización y clasificación de las unidades obtenidas en base a criterios de diferenciación. El criterio fundamental de categorización fue semántico, es decir, se agruparon las unidades por similitudes en cuanto a su significado.

Se utilizó como marco de referencia para guiar la categorización de metáforas el estudio de Saban (2004), quien recogió un conjunto de metáforas sobre las imágenes metafóricas de los docentes a partir de un análisis de los artículos de revistas en diferentes bases de datos (por ejemplo, Gillis y Johnson, 2002; Hagstrom et al., 2000; Martínez, Sauleda y Huber, 2001; Oxford et al., 1998; Inbar, 
1996). Luego agrupó las metáforas en dos grandes perspectivas teóricas en educación caracterizadas como: 1) perspectiva centrada en el profesor $y / u$ orientada a la instrucción y 2) perspectiva centrada en el estudiante $\mathrm{y} / \mathrm{u}$ orientada al aprendizaje. El marco organizativo para la agrupación de las metáforas se basó en las relaciones entre el profesor, el estudiante y los objetivos de la educación. A partir de esta relación se levantaron diferentes categorías conceptuales que agrupan determinadas metáforas ejemplares, considerando sus aspectos destacados. Producto de esta categorización, Saban (2004, p. 625) establece que la perspectiva centrada en el profesor se enfoca más en la transmisión de conocimiento y la entrega de la instrucción; la perspectiva centrada en el estudiante, en cambio, se orienta más a la facilitación del aprendizaje y a la participación activa de los estudiantes.

Se consideró además las etapas propias del análisis de contenido para las metáforas, propuestas por Saban, Kocbeker y Saban (2007) y Moser (2000), entre las cuales destaca la etapa de clasificación (clarificación y eliminación), en la que se analiza cada metáfora para caracterizar sus elementos: (1) el dominio meta, (2) el dominio fuente. El dominio meta es el tema de la metáfora (en esta investigación, EL PROFESOR). El dominio fuente es el concepto con el que se compara el dominio meta. $\mathrm{Al}$ utilizar este enfoque, se pretende descomponer cada metáfora en partes analizables, buscando las características/imágenes prominentes, elementos comunes y similitudes entre las diversas metáforas. Asimismo, estos autores entregan lineamiento para explicitar las razones por las cuales dejar fuera del análisis respuestas al cuestionario.

No todos los estudiantes produjeron una metáfora válida analizable. En esta etapa, se eliminan las respuestas pobremente estructuradas según los siguientes criterios.

- Descripción normal o no mención de metáfora, por ejemplo: "el profesor es como un ser perseverante, porque quiere cambiar y mejorar la educación".
- Mención de una metáfora, pero sin entregar una fundamentación, por ejemplo: "el profesor es como la capa de ozono".

- Metáfora híbrida o difusa, o dificultad para incluir la metáfora en una categoría conceptual claramente reconocible, por ejemplo: "el profesor es como el llenador de vacíos y carencias que debe ser crucificado, porque e profesor es psicólogo, orientador, padre que forma y de no cumplir esto en sus 500 horas semanales es crucificado sin piedad por la sociedad".

En una primera instancia, cada investigador realizó la categorización por separado. Para asegurar la fiabilidad de los datos, en una segunda instancia, las categorizaciones obtenidas se sometieron a discusión grupal, a fin de lograr consenso. Para eliminar la subjetividad en el análisis, se pidió a tres jueces externos que agruparan todas las respuestas en las categorías definidas.

\section{Análisis de metáforas}

\section{1.er AÑO}

\section{Pregunta 1: En la sociedad chilena, el profesor en cuanto profesional de la educación es visto como... porque...}

Mediante esta pregunta se pretende recoger las creencias que tienen los sujetos acerca de cómo son vistos los profesores por la sociedad chilena. Los resultados se organizaron en tres categorías generales: Metáforas centradas en el estudiante, Metáforas centradas en el profesor y Metáforas centradas en la valoración social. Dentro de ellas hay categorías específicas (por ejemplo, Líder cooperativo), que agrupan metáforas (se escribe su dominio fuente, por ejemplo, pastor). En la tabla 1 se enuncian estas categorías generales, sus categorías específicas y sus respectivas metáforas (cuando se repite una metáfora se pone el número de ocurrencias entre paréntesis). Más abajo se comentan las categorías con mayor ocurrencia y se presentan algunas respuestas de los sujetos a modo de ejemplo. 
Universidad Pedagógica Nacional

Facultad de Humanidades

Tabla 1. Categorías y metáforas en 1.er año para la pregunta 1

\begin{tabular}{|c|c|c|c|}
\hline \multirow{2}{*}{ Centradas en el profesor } & \multirow{2}{*}{ Centradas en el estudiante } & \multicolumn{2}{|c|}{ Centradas en la valoración social } \\
\hline & & Valoración positiva & Valoración negativa \\
\hline $\begin{array}{l}\text { Transmisor de conocimientos } \\
\text { - biblioteca } \\
\text { - luz } \\
\text { - ancla }\end{array}$ & $\begin{array}{l}\text { Líder cooperativo } \\
\text { - pastor } \\
\text { - guía (2) } \\
\text { - guionista }\end{array}$ & $\begin{array}{l}\text { Héroe } \\
\text { - héroe }\end{array}$ & $\begin{array}{l}\text { Minusvalorado } \\
\text { - un dólar } \\
\text { - pantalón } \\
\text { - alcohol } \\
\text { - el pasado } \\
\text { - instrumento }\end{array}$ \\
\hline $\begin{array}{l}\text { Figura de autoridad superior } \\
\text { - un verdugo }\end{array}$ & $\begin{array}{l}\text { Cuidador } \\
\text { - padre (2) } \\
\text { - águila madre }\end{array}$ & $\begin{array}{l}\text { Parte de un todo } \\
\text { - una pieza de construcción }\end{array}$ & $\begin{array}{l}\text { Persona inadaptada } \\
\text { - el patito feo }\end{array}$ \\
\hline
\end{tabular}

Se clasificaron como metáforas 20 respuestas. Un sujeto no contestó. Además, se descartaron 8 respuestas por no constituir metáforas, sino descripciones literales acerca de la percepción social del rol docente. Se debe señalar que de estas, 6 respuestas corresponden a la categoría Minusvalorado y 2 a Transmisor de conocimientos.

Desde la perspectiva de las Metáforas centradas en el profesor el rol del docente consiste en entregar conocimientos a sus alumnos y hacer que cumplan reglas, de acuerdo con un modelo de sociedad determinado

Según las metáforas agrupadas en la categoría específica Transmisor de conocimiento, el docente desempeña el rol activo de entregar contenidos y los alumnos desempeñan el rol pasivo de recibirlos; por ejemplo:

1. El profesor es como una luz dentro de una habitación, que si no fuera por esa luz estaría completamente oscura, porque los profesores (algunos) nos hacen ver qué cosas hay en nuestro ámbito de estudio y nos enseñan a salir de ahí con la visión, el recuerdo de la habitación, ahora iluminada.

El profesor como figura de autoridad superior destaca el rol de vigilancia y control que tiene el profesor sobre los estudiantes. El profesor se encarga de hacer cumplir las reglas que el colegio impone, por ejemplo:

2. El profesor es como un verdugo, porque la mayoría de los estudiantes ven al profesor como estereotipo de una persona hostil, que se asegura de quitarles libertad.

3. (Es interesante destacar en estos hallazgos que las metáforas especifican claramente el control y la vigilancia que los poderes fácticos ejercen sobre la sociedad, con el fin de seguir moldeando de forma predeterminada) a las futuras generaciones. Además, la verticalidad imperante en las relaciones humanas en la sociedad chilena se evidencia en las metáforas explicitadas por los estudiantes.

De acuerdo con la categoría general Metáforas centradas en el estudiante, se configura al profesor en su tarea de facilitar el proceso de formación académica y humana de los estudiantes, quienes tienen un rol activo en el proceso de enseñanza y aprendizaje. Además, el profesor tiene una posición de liderazgo y genera las condiciones para que sus estudiantes aprendan.

En la categoría específica Líder cooperativo se destaca el trabajo conjunto y en armonía, la participación activa y cooperación entre el profesor y sus alumnos; el aprendizaje se concibe como una exploración por parte de los alumnos, en la cual el profesor tiene el rol de conducirlos.

4. El profesor es como el pastor que debe criar al rebaño de ovejas a como dé lugar, porque debe educar a sus pupilos enseñándoles cosas que a veces deberían haber aprendido en sus casas, como por ejemplo valores y respeto. 
La categoría El profesor como cuidador subraya el rol docente de fomentar las capacidades de los estudiantes y velar por su formación personal; por ejemplo:

5. El profesor es como un padre, porque los niños y jóvenes pasan la mayor parte del tiempo en los colegios y son los profesores quienes les enseñan en cuanto a contenidos y también valóricamente.

Además de metáforas organizadas en categorías basadas en el proceso de enseñanza y aprendizaje, en este estudio se encontraron también metáforas que se agruparon en la categoría general Metáforas centradas en la valoración social del profesor. Esta categoría responde al contexto educacional chileno, al que se aludió en la introducción al presente artículo. De este modo, aunque la profesión docente pueda ser considerada como fundamental para el desarrollo del país, las constantes exigencias a los profesores en términos de las mediciones en pruebas estandarizadas y el nivel de remuneraciones inciden en un bajo reconocimiento social, que se traduce en una falta de interés por seguir la carrera docente.

En particular, en la categoría Minusvalorado, las respuestas de los estudiantes de primer año de pedagogía revelan que los sujetos tienen la creencia de que, según la sociedad, el profesor es menospreciado, de que se elige la carrera de pedagogía porque tiene pocas exigencias y de que la profesión docente no tiene futuro.

6. El profesor es como un dólar, porque aunque son necesarios en la sociedad para la educa- ción de la población, no se les da el valor que merecen, puesto que su trabajo fuera del aula no es reconocido.

Relacionada con la categoría anterior, la categoría Inadaptado configura al profesor como una persona que, al ser mirada como inferior, es marginada por la sociedad.

7. El profesor es como el patito feo, porque al igual que al patito feo, dentro de su grupo, el profesor es mirado diferente por los demás.

En el marco de las categorías anteriores se comprende que se configure al profesor como un héroe, pues, a pesar del desprecio social y de las dificultades propias de la profesión, enfrenta las adversidades y desarrolla su labor. Incluso se le atribuyen capacidades superiores para enfrentar sus funciones:

8. El profesor es como un héroe porque se esfuerza y lucha por un grupo de personas para que salgan adelante.

A pesar de la evidente baja valoración social que posee la profesión docente, buena parte de los alumnos tiene conciencia de la importancia del rol que cumple el profesor en la sociedad.

\section{Pregunta 2: Según su opinión, en el proceso de enseñanza-aprendizaje de la lengua, el profesor de inglés es como... porque...}

A través de esta pregunta se pretende identificar la imagen que tienen los sujetos sobre el rol del profesor de inglés. En la tabla 2 se presentan las categorías y metáforas encontradas.

Tabla 2. Categorías y metáforas en 1.er año para la pregunta 2

\begin{tabular}{|c|c|c|c|}
\hline Centradas en el profesor & $\begin{array}{l}\text { Centradas en } \\
\text { el estudiante }\end{array}$ & $\begin{array}{l}\text { Centradas en la val- } \\
\text { oración social }\end{array}$ & $\begin{array}{l}\text { Centradas en el desar- } \\
\text { rollo profesional }\end{array}$ \\
\hline $\begin{array}{l}\text { Transmisor de conocimientos } \\
\text { - un conductor de auto } \\
\text { - una luz (3) } \\
\text { - un diccionario (2) } \\
\text { - un libro }\end{array}$ & $\begin{array}{l}\text { Facilitador } \\
\text { - una ventana } \\
\text { - puente (2) } \\
\text { - un vendedor de llaves } \\
\text { - un faro }\end{array}$ & $\begin{array}{l}\text { Héroe } \\
\text { - un héroe (2) }\end{array}$ & $\begin{array}{l}\text { Persona en crecimiento } \\
\text { - un niño (2) }\end{array}$ \\
\hline \multirow[t]{2}{*}{$\begin{array}{l}\text { Figura de autoridad superior } \\
\text { - un comandante en tiempos de } \\
\text { guerra }\end{array}$} & $\begin{array}{l}\text { Líder cooperativo } \\
\text { - guía turístico } \\
\text { - guía }\end{array}$ & $\begin{array}{l}\text { Extraño } \\
\text { - un extraterrestre } \\
\text { - un trabalenguas }\end{array}$ & $\begin{array}{l}\text { Animal en crecimiento } \\
\text { - una oruga }\end{array}$ \\
\hline & $\begin{array}{l}\text { Cuidador } \\
\text { - una madre } \\
\text { - un padre }\end{array}$ & & $\begin{array}{l}\text { Materia prima } \\
\text { - un diamante }\end{array}$ \\
\hline
\end{tabular}


Se clasificaron como metáforas 25 respuestas. Hubo dos omisiones. Además, se descartaron 2 respuestas por corresponder a descripciones: una corresponde a la categoría Minusvalorado y otra a Transmisor de conocimientos.

Dentro de la categoría general Metáforas centradas en el profesor, la categoría Transmisor de conocimientos es donde aparece la mayor cantidad de respuestas. En la respuesta siguiente se destacan aspectos propios de la especialidad:

9. El profesor de inglés es como un diccionario parlante, porque puede enseñarte tantas significaciones, definiciones, como también saber expresarte en ese idioma.

La categoría Metáforas centradas en el estudiante es donde hubo mayor cantidad de respuestas para la pregunta 2. Dentro de ella, en la categoría específica Facilitador se destaca que el docente propicia el aprendizaje de una lengua extranjera con lo cual permite acceder a una cultura diferente.

10. El profesor de inglés es como un puente conector de mundos, porque transforma la realidad de las personas y les entrega nuevas oportunidades a las personas.

En la categoría Líder cooperativo, el proceso de enseñanza y aprendizaje se configura en términos de descubrimiento y exploración, con participación activa de los estudiantes, quienes son guiados por el profesor.

11. El profesor de inglés es como un guía turístico, porque te muestra lo mejor de otra cultura y una forma de entender el mundo.

En la categoría Cuidador se destaca que el rol del profesor es satisfacer las necesidades de los alumnos y brindarles apoyos en su proceso de aprendizaje, por ejemplo:

12. El profesor de inglés es como una madre, porque está contigo muchas veces en tus primeras palabras en el idioma y te ayuda a levantarte cuando caes.
En las Metáforas centradas en la valoración, hay metáforas con valoración positiva (héroe) y otras que atienden a la enseñanza de una lengua extranjera, por ejemplo:

13. El profesor de inglés es como un extraterrestre, porque al menos en Chile es desconocido el idioma extranjero por lo que se asimila a una cultura distinta que nos enseña e instruye en algo mejor.

Las Metáforas centradas en el desarrollo profesional destacan que esta profesión requiere de un constante perfeccionamiento y actualización para poder desenvolverse correctamente en una lengua extranjera.

14. El profesor de inglés es como un niño pequeño que aprende nuevas palabras que sólo las escucha y no entiende mucho, pero trata de comunicarse, porque a ambos les cuesta aprender un lote de palabras y significados, pero que con el tiempo saben desenvolverse en el mundo.

A diferencia de la pregunta anterior, que manifiestan las complejidades que enfrentan los docentes en el contexto chileno, en esta pregunta, los sujetos se centran en el proceso educativo, en la formación profesional permanente. Las metáforas recogidas otorgan una valoración positiva al profesor de inglés, quien permite introducir a los alumnos en una lengua y cultura diferentes.

\section{5. ${ }^{\circ}$ AÑO}

\section{Pregunta 1: En la sociedad chilena, el profesor en cuanto profesional de la educación es visto como... porque...}

Se presentan a continuación, las categorías y metáforas recogidas de los estudiantes de $5 .^{\circ}$ año para la pregunta 1 . 
Tabla 3. Categorías y metáforas en $5 .^{\circ}$ año para la pregunta 1

\begin{tabular}{|c|c|c|c|}
\hline \multirow{2}{*}{$\begin{array}{l}\text { Centradas en } \\
\text { el profesor }\end{array}$} & \multirow{2}{*}{$\begin{array}{c}\text { Centradas en el } \\
\text { estudiante }\end{array}$} & \multicolumn{2}{|c|}{ Centradas en la valoración social } \\
\hline & & Valoración positiva & Valoración negativa \\
\hline $\begin{array}{l}\text { Artesano } \\
\text { - Pintor }\end{array}$ & $\begin{array}{l}\text { Cuidador } \\
\text { - Padre o madre (4) }\end{array}$ & $\begin{array}{l}\text { Trabajador } \\
\text { - una hormiga }\end{array}$ & $\begin{array}{l}\text { Empleado } \\
\text { - Proveedor de un servicio (2) } \\
\text { - Computador multifuncional } \\
\text { - Guardaespaldas }\end{array}$ \\
\hline & & & $\begin{array}{l}\text { Minusvalorado } \\
\text { - El pariente pobre } \\
\text { - Un perro quiltro (2) }\end{array}$ \\
\hline
\end{tabular}

Se clasificaron como metáforas 13 respuestas. Se descartaron 2 respuestas: una por corresponder a descripción, dentro de la categoría Minusvalorado, y otra porque no hubo consenso para su clasificación.

Dentro de la categoría general Metáforas centradas en el estudiante, se encontraron dos perspectivas desde la cual se constituye la categoría de Cuidador, ambas expresadas a través del concepto de progenitor. Por una parte, se configura al padre o madre como cuidador en cuanto se destaca su rol de preocupación, cuidado y formación de lazos afectivos con sus alumnos (14); por otra parte, se destaca que al profesor se le delegan responsabilidades propias de la familia, sin atender, necesariamente, a su dimensión educativa (15).

15. El profesor es como la segunda madre o padre del hogar, porque al pasar casi la mayor parte del tiempo con sus estudiantes, se establece en algunos casos una mayor cercanía con ellos, en el cual se conocen sus alegrías o problemas que puedan enfrentar en el hogar, además de tratar de solucionarlos.

16. El profesor es como un padre, porque la sociedad cree que son los profesores los que deben educar en todo ámbito a los jóvenes y niños y generalmente, son los mismos padres los que delegan esas funciones propias de ellos a los profesores.

Los ejemplos anteriores explicitan que los sujetos mantienen la idea del educador como un padre o madre, lo que evidencia la fuerte significación que posee el sistema educativo actual como cuidadores de los hijos mientras los padres trabajan. Es impor- tante destacar, además, que esta conceptualización metafórica de los estudiantes se presenta en los estudiantes de primer y quinto año.

En la categoría Metáforas centradas en el profesor, se encontró solo una metáfora en esta categoría, según la cual el profesor es el artista y el estudiante materia prima que es moldeada por el profesor.

17. El profesor es como un pintor, porque no todos son capaces de ver lo hermoso de su obra. Porque así como cada cuadro que un pintor crea, cada alumno sale con un sello personal de los profesores que tuvo, sea éste bueno o malo. Porque cada pintor y cada profesor tiene su técnica, su ritmo y refleja su personalidad y dedicación en cada una de sus pinceladas. Y siempre hay alguien entre la multitud que se da vuelta para admirar el magnífico trabajo que ha hecho.

En la categoría general Metáforas centradas en la valoración social, hay categorías con valoración negativa y positiva. Dentro de esta última, se encontró solo una metáfora, la cual destaca la abnegación y dedicación en la función docente.

18. El profesor es como una hormiga, porque al igual que una hormiga trabaja sin descanso para mantener el hormiguero, el profesor trabaja son descanso para y por sus estudiantes.

Se debe destacar que en este grupo la mayor cantidad de metáforas se encuentra en la categoría de valoración social negativa. De acuerdo con la categoría específica Empleado, la educación es un bien de consumo que el profesor ofrece a sus clientes, los 
alumnos. El profesor tiene que cumplir múltiples funciones, fuera, incluso, del proceso de enseñanza aprendizaje.

19. El profesor es como proveedor de un servicio, porque hoy en día la educación es vista como un bien de consumo y en ese sentido, los profesores son vistos como los que proveen el servicio. Si hay un problema con la educación, los profesores son a quienes se les culpa inmediatamente, ya que son ellos los que dan la cara.

Es evidente la lógica economicista que poseería el sistema educativo y que se refleja en y traspasa a los estudiantes.

Según la categoría Minusvalorado, la profesión docente está en un lugar inferior con respecto a las otras profesiones; el profesor carece de reconocimiento social y está sujeto a críticas.

20. El profesor es como el pariente pobre, porque es uno de los que más trabaja, pero es uno de los menos recompensados. Todos se sienten con el derecho de criticarlo, todos se sienten con el derecho a decir que lo que hace está mal. Al pariente pobre todos lo critican porque lo ven como culpable de su propia suerte, al profesor todos lo critican por ser culpable de la calidad de la educación en nuestro país.
Como se ha señalado, la carrera docente ocupa un lugar inferior en relación con las otras profesiones. A través de esta pregunta, los sujetos que están terminando su formación universitaria manifiestan la creencia de que la carrera docente es fuertemente cuestionada por la sociedad y que, en último término, se ha desprofesionalizado: los profesores se ven sometidos a múltiples exigencias y deben desempeñar funciones que no se relacionan con su formación pedagógica necesariamente, es decir, simplemente seguirían instrucciones realizadas por otro a modo de manual, no utilizando el razonamiento para la solución de problemas, por ejemplo. Lo anterior tiene relación con el planteamiento de Hoyle (1974, en Ávalos, 2013), quien señala esta tendencia en la práctica a una cuasi-profesión. Como consecuencia, estudiar pedagogía no está entre las alternativas más requeridas. Esta minusvaloración explicaría los esfuerzos gubernamentales para motivar el ingreso a las carreras de pedagogía a través de becas específicas y de incentivos económicos a los profesores en ejercicio.

\section{Pregunta 2: Según su opinión, en el proceso de enseñanza-aprendizaje de la lengua, el profesor de inglés es como...}

A continuación se presentan las categorías y metáforas recogidas para la pregunta 2 , las cuales se resumen en la tabla 4.

Tabla 4. Categorías y metáforas en $5 .^{\circ}$ año para la pregunta 2

\begin{tabular}{|l|l|l|}
\hline \multicolumn{1}{|c|}{ Centradas en el profesor } & \multicolumn{1}{|c|}{ Centradas en el estudiante } & \multicolumn{1}{c|}{ Centradas en valoración social } \\
\hline $\begin{array}{l}\text { Constructor } \\
\text { - un constructor (3) }\end{array}$ & Líder cooperativo & Extranjero \\
\hline - un alfarero & - un baterista & - un extranjero \\
\hline $\begin{array}{l}\text { Transmisor de conocimientos } \\
\text { - una luz }\end{array}$ & - el director creativo de una compañía & \\
& - un guía turístico & \\
& Animador & \\
& - un infomercial & \\
& - un actor \\
& - un teléfono celular & \\
\hline & Cuidador \\
\hline & - un jardinero \\
\hline & - un hermano mayor \\
\hline
\end{tabular}


Dentro de las Metáforas centradas en el profesor, la categoría específica Constructor fue la más numerosa. Según esta, el proceso de enseñanza y educación corresponde al proceso de construcción, los estudiantes son la construcción a realizar, los conocimientos son las bases para edificarla sólidamente y el profesor es el encargado de llevar a cabo esta tarea, como se observa en:

21. El profesor de inglés es como un constructor, porque para que la casa (alumnos) pueda crecer se debe ir construyendo todo de a poco. No se puede construir el techo de una casa sin antes tener los cimientos y las vigas que soportarán el edificio. Un profesor debe hacer lo mismo, ir paso a paso sin saltarse etapas.

La categoría Metáforas centradas en el estudiante es donde se obtuvo el mayor número de metáforas para esta pregunta. Según las metáforas de la categoría Líder cooperativo el proceso educativo consiste en un constante descubrimiento y exploración, proceso en el cual son guiados y motivados por sus profesores. Las metáforas destacan también el trabajo en conjunto y la cooperación entre los participantes de este proceso.

22. El profesor de inglés es como un baterista, porque marca el ritmo en todas las canciones, es parte esencial en todo tipo de bandas musicales del estilo que sean, pero a pesar de su gran importancia, ya que ni una canción sería lo mismo sin batería, nunca será el frontman de la banda.

23. El profesor de inglés es como un guía turístico, porque el profesor de inglés está encargado de enseñar los aspectos más importantes y característicos del idioma de una forma interesante y atractiva. Para ello, debe llevarlos a un contexto que sea motivador y significativo, con la finalidad de mostrar las grandes atracciones y oportunidades que el inglés les pueda brindar.

De acuerdo con la categoría Animador, el profesor satisface la curiosidad de los estudiantes mediante estrategias que capten su atención y los motiven, tal como se muestra en (23) o en (24), que, aunque está en el marco de la educación como un bien de consumo, destaca la realización de diferentes actividades usadas por los docentes en su desempeño en el aula.

24. El profesor de inglés es como un actor, porque de la misma forma en que un actor juega el rol de un personaje, el profesor de inglés debe adoptar diversos roles en el aula, en especial, cuando enseña contenidos contextualizados.

25. El profesor de inglés es como un infomercial, porque tratamos que los alumnos se entusiasmen con la asignatura, que compren nuestro "producto", lo hacemos lo más atractivo posible con gran variedad de actividades que se asemejan a la gran cantidad de usos de un producto ofrecido en un infomercial.

A diferencia de la pregunta 1 , y de manera similar a lo que ocurre con los sujetos de primer año, en la pregunta 2 no hay categorías con valoración social negativa; en su lugar, se encontró la siguiente respuesta que atiende a las particularidades propias de la enseñanza de una lengua extranjera:

26. El profesor de inglés es como un extranjero, porque comúnmente es el que acerca a los estudiantes a otras formas de cultura a través de otro idioma y el tipo de actividades que realiza.

Los sujetos de $5 .^{\circ}$ año, si bien están conscientes de las dificultades que probablemente enfrentarán cuando comiencen su ejercicio profesional (como se evidencia en la pregunta 1), manifiestan creencias centradas en roles educativos y con una valoración positiva. Sin embargo, como quedó en evidencia en la primera pregunta, hay ideas, planteamiento (no sé cómo llamar este concepto) que se mantienen durante la formación universitaria y que se mantendrían incluso durante el ejercicio de la profesión.

\section{Conclusiones}

En este estudio hemos trabajado con el supuesto de que las metáforas son una fuente válida para indagar en el proceso de enseñanza y aprendizaje desde 
las perspectivas de diferentes actores del sistema educativo.

En los resultados obtenidos con respecto a la pregunta 1, en el grupo de estudiantes de $1 .{ }^{\mathrm{er}}$ año, se identificaron categorías enmarcadas en el proceso de enseñanza y aprendizaje. Las categorías centradas en el estudiante configuran al docente en el rol de permitir que los alumnos desarrollen sus potencialidades; en cambio, las categorías centradas en el profesor, en esta pregunta, destacan la transmisión y recepción de contenidos, con lo cual al alumno se le asigna un rol pasivo. Además, los sujetos muestran tener conciencia de la minusvaloración social que recibe la profesión docente. En el grupo de estudiantes de $5 .^{\circ}$ año se observa que los sujetos que están terminando su formación muestran también estar conscientes de esta valoración negativa asignada a los profesores. Se le reconoce también un rol social de formadores de los alumnos, pero muchas veces desempeñando funciones que les corresponden a los padres. Los aspectos destacados por las metáforas permiten evidenciar una percepción sobre la desprofesionalización de la carrera docente, donde no importa cuán bien desempeñen su rol pedagógico, sino la forma en que sirven a un modelo económico que requiere que alguien esté al cuidado de los niños. Estudios futuros podrían indagar en cuáles son los factores del contexto social en el que se basan estas creencias; asimismo, habría que investigar las percepciones sociales sobre la labor docente de sujetos que no son actores directos del sistema educativo para analizar las imágenes existentes sobre los profesores y las valoraciones que conllevan, y, en última medida, establecer su relación con la autoimagen de los docentes.

En la pregunta 2, en ambos grupos desparecen las categorías centradas en valoraciones negativas. No obstante, se debe destacar una diferencia entre el grupo de $1 .^{\text {er }}$ año y el de $5 .^{\circ}$. En el primero, la categoría más numerosa es la que configura el rol del profesor en el proceso de enseñanza y aprendizaje como transmisor de conocimientos. Esto puede entenderse como la manifestación del modelo de enseñanza que estos sujetos tuvieron en la ense- ñanza secundaria y, habría que indagar si es también el modelo que esperan de sus profesores universitarios. Que la categoría Facilitador sea la segunda más numerosa es un dato que puede servirle a la institución formadora para promover este rol en los futuros profesores. A diferencia del grupo de 1. ${ }^{\text {er }}$ año, en el grupo de estudiantes de $5 .^{\circ}$, hay un predominio de las metáforas centradas en el estudiante. Esta categoría se centra en el desempeño en el aula y las estrategias didácticas para lograr el aprendizaje en sus alumnos. También tiene una figuración importante la categoría Constructor, que, si bien está centrada en los contenidos, le asigna al profesor la responsabilidad de formar de manera rigurosa a sus estudiantes. Se debe recordar que a este grupo el instrumento se le aplicó en la etapa final de su formación universitaria cuando ya había finalizado su práctica pedagógica.

Los datos obtenidos pueden considerarse desde las perspectivas de enseñanza y aprendizaje de lenguas. Por una parte, desde el enfoque conductista se observa el rol central del profesor, visualizado como modelo y modelador de la lengua. En la década de los setenta cobra relevancia el enfoque comunicativo, donde el rol del profesor es guiar y facilitar el aprendizaje de sus alumnos, quienes tienen un papel activo en el proceso. De acuerdo con las categorías obtenidas, los estudiantes de $5 .^{\circ}$, que ya han tenido experiencia profesional en el aula, ofrecen una imagen mucho más cercana al enfoque comunicativo, orientando sus metáforas a la motivación y participación de los alumnos en el aprendizaje de una lengua extranjera.

Con respecto a la metodología del estudio, el instrumento para recoger metáforas sirvió para que los sujetos pudieran producir conceptos metafóricos, independiente del medio (en el aula o vía internet). La pregunta con menos respuestas válidas fue la 1 en el grupo de $1 .^{\text {er }}$ año. Se debe recalcar que para que el instrumento sea efectivo hay que indicarles a los sujetos los objetivos de la investigación en la que se enmarca. Esto permite que valoren la importancia que sus respuestas tendrán y que tomen con responsabilidad y seriedad su participación. 
En lo relativo al análisis de contenido, la fase de categorización fue la más extensa, dado que en algunas respuestas no se logró acuerdo entre los investigadores, en casos donde no había consenso en si el dominio fuente era en realidad parte del dominio meta, por ejemplo, cuando se conceptualiza al profesor como tutor. Se les pidió a tres jueces externos que agruparan todas las respuestas en las categorías definidas. Con esta etapa, se logró el acuerdo definitivo acerca de las respuestas que no correspondían a metáfora, en lo cual hubo acuerdo total y también se dejaron fuera los casos problemáticos, es decir, las metáforas en las cuales no hubo consenso sobre su inclusión en una categoría determinada.

Consideramos que este tipo de estudio puede aún mejorarse, por ejemplo, procurando fortalecer la validez de sus resultados a través de otros métodos. A partir de esta y otras investigaciones que se han venido realizando desde hace tres años, este equipo está diseñando la aplicación de focus group como una instancia posterior al cuestionario, a fin de profundizar en las explicaciones que los sujetos dan a sus creencias. Interesa, en última medida, elaborar instrumentos que puedan ser replicados en otros contextos y relacionar los resultados del análisis cualitativo con variables sociodemográficas, tales como género, edad, tipo de establecimiento y nivel socioeconómico.

Es de esperar que estos resultados permitan a las instituciones formadoras de docentes explicitar y discutir los enfoques de enseñanza y aprendizaje que se pretende sean aplicados al aula por los futuros profesores, al mismo tiempo que se analice con ellos los aspectos más críticos de las creencias sociales y personales sobre el rol docente, dado que estas creencias pueden afectar su desempeño profesional y su motivación para la el ejercicio profesional.

\section{Referencias}

Ávalos, B. (2013). ¿Héroes o villanos? La profesión docente en Chile. Santiago de Chile: Editorial Universitaria.

Bardin, L. (1996). Análisis de contenido. Madrid: Akal.
Ben-Peretz, M., Mendelson, N. y Kron, F. (2003). How teachers in Different Educational Contexts View their Roles. Teaching and Teacher Education, 19, 277-290.

Borg, S. (2003). Teacher cognition in language teaching: a review of research on what language teachers think, know, believe, and do. The International Abstracting Journal for Language Teachers and Applied Linguists, 36, 81-109.

Black, A. y Halliwell, G. (2000). Accessing practical knowledge: how? why? Teaching and Teacher Education, 16, 103-115.

Bozlk, M. (2002). The college student as learner: insight gained through metaphor analysis. College Student Journal, 36(1), 142-151.

Brandt, N. (2010). Chile: Climbing on giants' shoulders: Better schools for all Chilean children. Economics Department, working paper 784. Disponible en: http://search.oecd.org/officialdocuments/disp laydocumentpdf $/$ ?doclanguage $=e n \& \operatorname{cote}=e c o /$ $w k p(2010) 40$

Cameron, L. (2003). Metaphor in educational discourse. Londres: Continuum.

Casasanto, D. (2014). Experiential origins of mental metaphors: Language, culture, and the body. En Mark Landau, Michael Robinson y Brian Meier (Eds.), The power of metaphor. Examining its influence on social life (pp. 249-268). Washington, DC: American Psychological Association.

Chilton, P. (2004). Analysing political discourse: Theory and practice. Londres: Routledge.

Cienki, A., y Müller, C. (Eds.) (2008). Metaphor and gesture. Amsterdam: John Benjamins.

Cortazzi, M., y Jin, L. (1999). Bridges to learning: Metaphors of teaching, learning and language. En L. Cameron y G. Low (Eds.), Researching and applying metaphor (pp. 149-176). Cambridge, UK: Cambridge University Press.

Cuadrado, G., y Robisco, M. (2011). Aplicaciones didácticas de la metáfora cognitiva al aprendizaje del inglés para la ciencia y la tecnología. Revista de Lingüística $y$ Lenguas Aplicadas, 6, 95-106.

Díaz, Á. (2011). La imagen metafórica publicitaria. Cuadernos de Lingüística Hispánica, 18, 27-42.

Eren, A., y Tekinarslan, E. (2013). Prospective teachers' metaphors: teacher, teaching, learning, instructional material and evaluation concepts. International J. Soc. Sci. \& Education, 3(2), 435-445. 
Evans, V., y Green, M. (2006). Cognitive linguistics. An introduction. Edimburgo: Edinburgh University Press, Ltd.

Freeman, D. (2002). The hidden side of the work: Teacher knowledge and learning to teach. A perspective from North American educational research on teacher education in English language teaching. Language Teaching. The International Abstracting Journal for Language Teachers and Applied Linguists, 35, 1-13.

Geeraerts, D., y Cuyckens, H. (2007). Introducing cognitive linguistics. En D. Geeraerts y H. Cuyckens (Eds.), The Oxford handbook of cognitive linguistics (pp. 3-21). Oxford: Oxford University Press.

Gillis, C., y Johnson, C. (2002). Metaphor as renewal: reimagining our professional selves. English Journal, 91(6), 37-43.

González, S., y Montealegre, J. (Eds.) (2012). Ciudadanía en marcha: Educación superior y movimiento estudiantil 2011: Curso y lecciones de un conflicto. Santiago, Chile: USACH.

Grady, J. (2007). Metaphor. En D. Geeraerts y H. Cuyckens (Eds.), The Oxford handbook of cognitive linguistics (pp. 188-213). Oxford: Oxford University Press.

Guerrero de, M., y Villamil, O. (2001). Metaphor analysis in second/foreign language instruction: A sociocultural perspective. Revised version of paper presented at the annual meeting of the American Association of Applied Linguistics, St. Louis, MO, February, pp. 24-27.

Hagstrom, D., Hubbard, R., Hurtig, C., Mortola, P., Ostrow, J., White, V. (2000). Teaching is like...? Educational Leadership, 57, 24-27.

Ibarretxe-Antuñano, I., y Valenzuela, J. (2012). Lingüística cognitiva: Origen, principios y tendencias. En I. Ibarretxe-Antuñano y J. Valenzuela (coords.), Lingüística cognitiva (pp. 13-38). Barcelona: Anthropos.

Inbar, D. (1996). The free educational prison: metaphors and images. Educational Research, 38(1), 77-92.

Kasoutas, M., y Malamitsa, K. (2009). Exploring Greek teachers' beliefs using metaphors. Australian Journal of Teacher Education, 34(2), 64-83.

Kövecses, Z. (1990). Emotion concepts. New York: Springer-Verlag.
Kövecses, Z. (2002/2010). Metaphor: A practical introduction [2. ${ }^{\mathrm{e}}$ ed.]. Oxford/Nueva York: Oxford University Press.

Kramsch, C. (2003). Metaphor and the subjective construction of beliefs. En P. Kalaja y A. M. Barcelos (Eds.), Beliefs about SLA: New research approaches (pp. 109-128). Dordrecht: Kluwer Academic Publishers.

Lakoff, G. (1993). The contemporary theory of metaphor. En A. Ortony (Ed.), Metaphor and thought (pp. 202251). Cambridge: Cambridge University Press.

Lakoff, G., y Johnson, M. (1980). Metaphors we live by. Chicago: University of Chicago Press.

Lakoff, G., y Núñez, R. (2000). Where mathematics comes from: How the embodied mind brings mathematics into being. Nueva York: Basic Books.

Low, G. (2008). Metaphor and education. En Raymond Gibbs (Ed.), The Cambridge handbook of metaphor and thought (pp. 212-231). Cambridge: Cambridge University Press.

Marshall, H. (1990). Metaphor as an instructional tool in encouraging student teacher reflection. Theory into Practice, 29(2), 128-132.

Martínez, M., Sauleda, N., Huber, G. (2001). Metaphors as blueprints of thinking about teaching and learning. Teaching and Teacher Education, 17(8), 965-977.

Meller, P. y Brunner, J. (Coords). Futuro Laboral 2009/2010. Profesionales y técnicos en Chile: información fundamental. Santiago, Chile: Ediciones Universidad Diego Portales. Disponible en www. futurolaboral.cl y en http://ww2.educarchile.cl/ UserFiles/P0001/File/CR_Articulos/futuro_laboral_estudio.pdf

Merrian, S. (1998). Qualitative research and case study applications in education. San Francisco, CA: Jossey-Bass.

Moser, K. (2000). Metaphor analysis in psychology: method, theory, and fields of application. Forum: Qualitative Social Research, 1(2). Disponible en http://www.qualitative-research.net/fqs-texte/200/2-00moser-e.htm

Nikitina, L., y Furuoka, F. (2008). A language teacher is like...: Examining Malaysian students' perceptions of language teachers through metaphor analysis. Electronic Journal of Foreign Language Teaching, 5(2), 192-205. 
Northcote, M. (2009). Educational beliefs of higher education teachers and students: implications for teacher education. Australian Journal of Teacher Education, 34(3), 69-81.

Oxford, R., Tomlinson, S., Barcelos, A., Harrington, C., Lavine, R., Saleh, A., Longhini, A. (1998). Clashing metaphors about classroom teachers: Toward a systematic typology for the language teaching field. System, 26(1), 3-50.

Pajares, M. (1992). Teachers' Beliefs and Educational Research: Cleaning up a Messy Construct. Review of Educational Research, 62, 307-332.

Richards, K., Ross, S. y Seedhouse, P. (2012). Research methods for applied language studies. An advanced resource book for students. Londres: Routledge.

Rodríguez, G., Gil, J., y García, E. (1999). Metodología de investigación cualitativa. Granada: Ediciones Aljibe.

Saban, A. (2004). Prospective classroom teachers' metaphorical images of selves and comparing them to those they have of their elementary and cooperating teachers. International Journal of Educational Development, 24(6), 617-635.

Saban, A. (2006). Functions of metaphor in teaching and teacher education: A review essay. Teaching Education, 17(4), 299-315.

Saban, A. (2010). Prospective teachers' metaphorical conceptualizations of learner. Teaching and Teacher Education, 26, 290-305.

Saban, A., Kocbeker, B. N., Saban, A. (2007). Prospective teachers' conceptions of teaching and learning revealed through metaphor analysis. Learning and Instruction, 17(2), 123-139.

Sánchez, C. (2009). Formación de profesores en educación básica en Chile: el desafío del dominio disciplinar y pedagógico. Perspectivas educacionales, 10, 1-11.
Análisis de creencias sobre el rol docente en estudiantes chilenos de pedagogía en inglés a través de la metáfora conceptual Paola Alarcón Hernández, Jorge Vergara Morales, Claudio Díaz Larenas, David Poveda Becerra
Cound

Sealey, A. (2010). Researching english language. A resource book for students. Londres: Routledge.

Simonsen, E. (2012). Mala educación. Historia de la revolución escolar. Santiago, Chile: Debate.

Soriano, C. (2012). La metáfora conceptual. En I. Ibarretxe-Antuñano y J. Valenzuela (Coords.), Lingüística cognitiva (pp. 97-121). Barcelona: Anthropos.

Stefanowitsch, A. y Gries, S. Th. (Eds.), (2006). Corpusbased approaches to metaphor and metonymy. Berlín: Mouton de Gruyter.

Sweetser, E. (1990). From etymology to pragmatics: metaphorical and cultural aspects of semantic structure. Cambridge: Cambridge University Press.

Thomas, L. y Beauchamp, C. (2011). Understanding new teachers' professional identities through metaphor. Teaching and Teacher Education, 27(4), 762-769.

Tillema, H. (1998). Stability and change in student teachers' beliefs about teaching. Teachers and thinking: Theory and Practice, 4, 217-228.

Tobin, K. (1990). Changing metaphors and beliefs: A master switch for teaching? Theory into Practice, 29(2), 122-127.

Wan, W. (2011). An examination of the validity of metaphor analysis studies: Problems with metaphor elicitation techniques. Metaphor and the Social World, 1(2), 262-288.

Wan, W., Low, G., y Li, M. (2011). From students' and teachers' perspectives: Metaphor analysis of beliefs about EFL teachers' roles. System, 39(3), 403-415.

Zapata, G. y Lacorte, M. (2007). Pre-service and inservice instructors' metaphorical constructions of second language teachers. Foreign Language Annals, 40(3), 521-534. 